\title{
(1) \\ FAKTOR-FAKTOR YANG BERHUBUNGAN DENGAN PEMINATAN KONTRASEPSI PIL DAN SUNTIK DI WILAYAH KERJA PUSKESMAS GLOBAL TIBAWA
}

\author{
Melisa R. Baharu'1, Harismayanti², Andi Kurniati Naue $^{3}$ \\ 1,2,3) Program Studi S1 Keperawatan Fakultas Kesehatan Universiitas Muhammadiyah \\ Gorontalo \\ e-mail : Melisa.baharu@yahoo.com
}

\begin{abstract}
The purpose of this research is to know how factors (age, knowledge, and number of children) can influence contraception specialization, this research use analytical survey method with cross sectional approach. Conducted in global public health center of Tibawa Gorontalo Regency with the number of samples of 63 respondents taken using Purposive Sampling technique. Data analysis using chi-square statistic test with degree of significance 0,05. The result of the research showed that there was a significant correlation between age factor with the pill and injection contraception specialization ( $P$ value $0.007<0,05$ ), knowledge factor with pills and injections ( $P$ value $0.002<0,05)$, and $t$ he number of children with the Pill and Injectable contraception specialization ( $P$ value $0.009<0.05$ ).
\end{abstract}

Keywords : Contraception, Specialization, Knowledge

\begin{abstract}
ABSTRAK
Tujuan dari penelitian ini untuk mengetahui bagaimana faktor-faktor (umur, pengetahuan, dan jumlah anak) dapat mempengaruhi peminatan alat kontrasepsi, penelitian ini menggunakan metode survey analitik dengan pendekatan cross sectional. Dilakukan di Puskesmas Global Tibawa Kabupaten Gorontalo dengan jumlah sampel sebanyak 63 responden yang diambil dengan menggunakan teknik Purposive Sampling. Analisa data menggunakan uji statistic chi-square dengan derajat kemaknaan 0,05 . Hasil penelitian menunjukan ada hubungan yang signifikan antara faktor umur dengan peminatan alat kontrasepsi Pil Dan Suntik ( $P$ value 0.007 $<0,05)$, faktor pengetahuan dengan peminatan alat kontrasepsi Pil Dan Suntik $(P$ value $0.002<0,05)$, dan faktor jumlah anak dengan peminatan alat kontrasepsi Pil dan Suntik $(P$ value $0.009<0,05)$.
\end{abstract}

Kata Kunci : Kontrasepsi, Peminatan, Pengetahuan

\section{PENDAHULUAN}

Pertambahan jumlah penduduk merupakan masalah di suatu Negara apabila tidak disertai peningkatan kualitas hidupnya. Besarnya jumlah penduduk tidak diimbangi dengan segi kualitasnya. Hal ini dapat dilihat dari
Human Development Index (HDI) atau indeks pembangunan manusia di 179 negara di dunia, Indonesia hanya menempati urutan 111, sehingga pertumbuhan penduduk dapat menjadi beban dalam pembangunan 
di suatu negara (Erna Dalam Pontoh, 2015).

Negara kita dihadapkan pada permasalahan kependudukan antara lain : Tingginya tingkat pertambahan penduduk, distribusi penduduk yang tidak seimbang antara penduduk kota dan desa, distribusi yang timpang antara pulau jawa dan luar jawa, komposisi yang timpang antara usia produktif, dan kualitas penduduk yang masih rendah (Koes, 2014)

Jumlah penduduk Indonesia terus bertambah. Sejak tahun 1968 penduduk Indonesia bertambah dari 115 juta orang pada menjadi 147,5 juta orang pada tahun 1980 dan 179,9 juta orang pada tahun 1990. Laju pertumbuhan penduduk dalam kurun waktu 1971-1980 adalah 2,32\% per tahun sedangkan selama kurun waktu tahun 1980-1990 turun menjadi 1,97\% per tahun. Pada akhir PJPT I jumlah penduduk berjumlah 192,1 juta orang. Dengan demikian jumlah penduduk selama PJPT I telah bertambah sebanyak 77,1 juta orang atau $67 \%$ dari jumlah penduduk tahun 1968. Laju pertumbuhan penduduk tersebut diperkirakan akan terus menurun sehingga dalam kurun waktu 19901994 pertumbuhan penduduk diperkirakan menjadi 1,65\% per tahun. Jadi jelaslan usaha-usaha pembangunan di bidang kependudukan selama PJPT I telah berhasil menurunkan laju pertumbuhan penduduk secara berkelanjutan (Koes, 2014).

Jumlah penduduk Indonesia berdasarkan hasil sensus penduduk Indonesia tahun 2010 sebanyak 237,6 juta jiwa, terdiri atas 119,6 juta pria dan 118 juta wanita dengan laju pertumbuhan penduduk Indonesia sebesar $1,49 \%$ per tahun sehingga merupakan jumlah penduduk terbesar keempat didunia setelah China, India, dan Amerika Serikat. Pertumbuhan penduduk ini tentu saja berimplikasi secara signifikan terhadap perkembangan ekonomi dan kesejahteraan negara. Berdasarkan jumlah tersebut, maka setiap harinya penduduk Indonesia bertambah sebesar 9.027 jiwa. Setiap jam terjadi pertambahan pertumbuhan penduduk sebanyak 377 jiwa, bahkan setiap detik jumlah pertambahan penduduk masih tergolong tinggi yaitu sebanyak $1,04 \%$ (1 sampai 2 juta jiwa). Pertambahan penduduk di Indonesia umumnya bisa dikatakan 99,9\% disebabkan oleh kelahiran, sisanya berupa migrasi. Dengan. Oleh karena itu, dibentuklah suatu program Keluarga Berencana (KB) untuk mengatasi permasalahan di atas guna mencapai tujuan pembangunan jangka panjang bidang kesehatan (Hanafi, 2014).

Hartono (2010) menyatakan bahwa pemilihan alat kontrasepsi dipengaruhi beberapa faktor diantaranya pendidikan, pekerjaan, jarak pelayanan kontrasepsi, biaya, dukungan suami, dan pengetahuan. Umur adalah usia ibu yang secara garis besar menjadi indikator dalam kedewasaan dalam setiap pengambilan keputusan yang mengacu pada setiap pengalamannya. Tingkat pendidikan turut menentukan mudah tidaknya seseorang dalam menyerap dan memahami pengetahuan tentang manfaat, kelebihan dan kelemahan dalam menentukan alat kontrasepsi.

Saat ini banyak beredar berbagai macam alat kontrasepsi mulai pada alat kontrasepsi jangka pendek dan jangka panjang alat 
kontrasepsi hendaknya memenuhi syarat yaitu : aman pemakaiannya dan dapat dipercaya, efek samping yang merugikan tidak ada, lama kerjanya dapat diatur menurut keinginan, tidak mengganggu hubungan seksual, harganya murah dan dapat deterima oleh pasangan suami istri, pemilihan alat kontrasepsi dapat dipengaruhi oleh beberapa karakteristik akseptor KB seperti pengetahuan, jumlah anak (Hartono, 2010).

Menurut World Health Organization (WHO) Kontrasepsi hormonal sebagai salah satu alat kontrasepsi yang meningkat tajam. Cakupan pasangan subur hampir 380 juta pasangan menjalankan keluarga berancana dan 65 sampai 75 juta di antaranya terutama di negara berkembang menggunakan kontrasepsi hormonal seperti Pil, suntik dan implant. Kontrasepsi hormonal yang digunakan dapat memiliki pengaruh positif dan negatif terhadap berbagai organ wanita (WHO, 2009).

Indonesia merupakan Negara yang dilihat dari jumlah penduduknya menempati posisi keempat didunia (Cina, India, dan Amerika Serikat) , dengan laju pertumbuhannya yang masih relative tinggi. Esensi tugas program keluarga berencana (KB) dalam hal ini jelas yaitu menurunkan fertilitas agar dapat mengurangi beban pembangunan demi terwujudnya kebahagian dan kesejahteraan bagi rakyat dan bangsa Indonesia. Seperti yang disebutkan dalam UU No.10 Tahun 1992 tentang perkembangan kependudukan dan pembangunan keluarga sejahtera, definisi KB yakni upaya meningkatkan kepedulian dan peran serta masyarakat melalui pendewasaan usia perkawinan, pengaturan kelahiran, pembinaan ketahanan keluarga dan peningkatan kesejahteraan keluarga guna mewujudkan keluarga kecil, bahagia dan sejahtera (Hartono, 2010).

Berdasarkan data yang didapat dari Dinas Kesehatan Provinsi Gorontalo pasangan usia subur di Provinsi Gorontalo jumlah peserta KB aktif tahun 2016 adalah sebanyak $149.593(71 \%)$ yang terdiri dari akseptor KB suntik $45.381 \quad(30 \%)$ kondom 1.358 (1\%) pil 42.008 (28\%) IUD $4.251 \quad(3 \%)$ implant 14.200 (9\%).(Dinkes.2016).

Data yang diperoleh dari BKKBN Provinsi Gorontalo tahun 2016 diketahui bahwa jumlah peserta KB aktif sebanyak 174.132 yang terdiri dari akseptor AKDR 17.260 $(10,12 \%)$, akseptor MOW 4.521 (2,44\%), akseptor MOP 1059 (0,61\%), akseptor Kondom 3.656 (2,21\%), akseptor Implan 42.877 (24,62\%), akseptor KB Suntik 65.052 (37,36\%), akseptor Kondom $1.358 \quad(1 \%)$ (BKKBN, 2016)

Berdasarkan data dari Kabupaten Gorontalo pasangan usia subur jumlah peserta KB aktif adalah sebanyak 76.439 yang terdiri dari akseptor KB IUD 3.959(6.6\%) Implan 12.993 (21.6\%) Kondom 954(1.5\%) Suntik 27.608(45.9\%).

Hasil prasurvey di Puskesmas Tibawa Kecamatan Tibawa pada tahun 2016 diketahui peserta KB Suntik sebanyak 377 orang, AKDR 65 orang, Implant 156 orang, Pil 42 orang. Berdasarkan data diatas peminatan Pil dansuntik, kontrasepsi suntik lebih banyak di minati dibandingkan dengan ibu yang menggunakan KB pil. Peminatan 
terhadap kontrasepsi Pil dan suntik lebih tinggi karena alat kontrasepsi tersebut lebih mudah didapatkan dan praktis penggunaannya serta mitosmitos yang beredar dimasyarakat mengenai efek samping alat kontrasepsi jangka panjang sehingga menurunkan minat masyarakat untuk menggunakan alat jangka panjang.

\section{METODE PENELITIAN}

Jenis

penelitian

ini

menggunakan penelitian kuantitatif dan observasional dengan metode penelitian survey analitik yaitu survey atau penelitian yang mencoba menggali bagaimana dan mengapa fenomena kesehatan itu terjadi. Kemudian melakukan analisis dinamika korelasi antara venomena, baik antara faktor resiko dengan faktor efek, antara faktor resiko, maupun antar faktor efek (Natoadmojo, 2012)

Penelitian ini menggunakan pendekatan cross sectional yaitu suatu penelitian untuk mempelajari dinamika korelasi antara variable bebas dan terikat dengan cara pendekatan observasional atau pengumpulan data satu kali pengambilan data (point time approach) (Setiawan, 2010).

\section{HASIL DAN PENELITIAN}

Hasil penelitian mengenai karakteristik responden berdasarkan tingkat pendidikan terakhir responden yang ditampilkan pada Tabel 1 . Persentasi karakteristik responden berdasarkan tingkat pendidikan terakhir yang diambil dari data responden sebagai sampel sebanyak 63 orang, sebagian besar merupakan lulusan SMP yaitu sebanyak 20 responden $(31,7 \%)$, kemudian lulusan SMA sebanyak13 responden (20,6\%).
Hasil penelitian mengenai karakteristik responden berdasarkan jenis pekerjaan resdponden. Persentasi karakteristik responden berdasarkan jenis pekerjaan yang diambil dari dataresponden sebagai sampel sebanyak 63 orang, sebagian besar Bekerja sebagai IRT sebanyak 40 responden $(63,4 \%)$, sebagai PNS sebanyak 10 responden $(15,8 \%)$.

Tabel 1. Distribusi karakteristik responden

\begin{tabular}{llll}
\hline Karakteristik & Kategori & $\mathrm{N}$ & $(\%)$ \\
\hline Pendidikan & SD & 15 & 23,8 \\
& SMP & 20 & 31,7 \\
& SMA & 13 & 20.6 \\
& PT & 15 & 23,8 \\
Pekerjaan & IRT & 40 & 63.4 \\
& WIRASW & 13 & 20.6 \\
& ASTA & & \\
& PNS & 10 & 15,8 \\
\hline Total & & 63 & 100 \\
\hline
\end{tabular}

Sumber : Olahan data primer (2018)

\section{Analisis Univariat}

Berdasarkan faktor pengetahuan seperti yang ditampilkan pada Tabel 2. Didapatkan hasil penelitian mengenai tingkat pengetahuan responden yang diperoleh dari 63 responden yang berpengetahuan Cukup sebanyak 43 orang $(68,2 \%)$ dan 8 orang $(12,6 \%)$ responden memiliki tingkat pengetahuan yang kurang. Berdasarkan tabel 3. Dapat dilihat dari 63 responden yang dijadikan sampel penelitian, pada umumnya berusia 20 sampai 35 tahun sebanyak (61,9\%) dengan jumlah sebanyak 39 orang, dan yang berusia $<20$ tahun sebanyak (19,0\%) dengan jumlah 12 orang dan $>35$ tahun 
sebanyak (19,0\%) dengan jumlah 12 orang.

Berdasarkan tabel 4. Hasil penelitian Menunjukan bahwa sebanyak 38 responden $(60,3 \%)$ memiliki 2 sampai 3 anak, dan 12 responden (19,0\%) memiliki 1 anak.

Tabel 2. Distribusi frekuensi pengetahuan responden

\begin{tabular}{lll}
\hline Pengetahuan & $\mathrm{Fr}$ & $\%$ \\
\hline Kurang & 8 & 12,7 \\
Cukup & 43 & 68,3 \\
Baik & 12 & 19,0 \\
\hline Total & 63 & 100 \\
\hline
\end{tabular}

Sumber : Olahan data primer (2018)

Tabel 3 Distribusi Responden Menurut Kelompok Umur.

\begin{tabular}{|c|c|c|}
\hline $\begin{array}{l}\text { Umur } \\
\text { (Tahun) }\end{array}$ & $\mathrm{Fr}$ & $\%$ \\
\hline$<20$ & 12 & 19,0 \\
\hline $20-35$ & 39 & 61,9 \\
\hline$>35$ & 12 & 19,0 \\
\hline Total & 63 & $100 \%$ \\
\hline
\end{tabular}

Tabel 4. Distribusi Responden Berdasarkan Jumlah Anak

\begin{tabular}{lll}
\hline Jumlah anak & $\mathrm{Fr}$ & $\%$ \\
\hline $0-1$ & 12 & 19,0 \\
$2-3$ & 38 & 60,3 \\
$>3$ & 13 & 20,6 \\
\hline Total & 63 & 100 \\
\hline
\end{tabular}

Sumber : Olahan data primer (2018)

Tabel 5. Distribusi Responden Berdasarkan Jenis Kontrasepsi

\begin{tabular}{lll}
\hline Jenis Kontrasepsi & $\mathrm{Fr}$ & $\%$ \\
\hline KB PIL & 36 & 57,1 \\
KB SUNTIK & 27 & 42,9 \\
\hline Total & 63 & 100 \\
\hline \multicolumn{2}{l}{ Sumber : Olahan data Primer (2018) }
\end{tabular}

Berdasarkan Tabel 5. Dapat dilihat dari 63 responden yang dijadikan sampel penelitian, yang menggunakan KB Pil sebanyak 36 responden $(57,1 \%)$ dan yang menggunakan Suntik sebanyak 27 responden

Analisis Bivariat

Berdasarkan Tabel 6. didapatkan hasil ibu yang berpengetahuan Baik sebanyak 12 (19,0\%), 9 (14,2\%) diant aranya menggunakan alat kontrasepsi Suntik dan $3(4,76 \%)$ responden menggunakan Pil. Ibu yang berpengetahuan Cukup sebanyak 43 $(68,2 \%) . \quad 31 \quad(49,2 \%)$ diantaranya menggunakan kontrasepsi Pil, 12 (19,0\%) menggunakan kontrasepsi Suntik dan responden yang memiliki tingkat pengetahuan Kurang sebanyak 12 $(19,0), 9(14,2 \%)$ diantaranya menggunakan Kontrasepsi Suntik, dan $3 \quad(4,76 \%)$ menggunakan kontrasepi Pil.

Hasil uji yang telah dilakukan dengan menggunakan uji statistik ChiSquare test mendapatkan variable pengetahuan dengan penggunaan alat kontrasepsi Suntik dan alat kontrasepsi pil nilai p.value 0.002 $(<0,05)$. Ini berarti hipotesis nol $(\mathrm{HO})$ ditolak dan hipotesis alternative $(\mathrm{Ha})$ diterima. Artinya, ada hubungan antara pengetahuan dengan peminatan kontrasepsi Suntik dan pil Diperkuat juga nilai $X^{2}$ Hitung $(12,362)$ $<\mathrm{X}^{2}$ Tabel $(5,991)$ sehingga HO di tolak dan Ha diterima 
Tabel 6. Hubungan faktor pengetahuan dengan Peminatan Kontrasepsi Pil dan Suntik.

\begin{tabular}{lllllllll}
\hline \multirow{2}{*}{ Tingkat } & \multicolumn{9}{c}{ Jenis kontrasepsi } & \multirow{2}{*}{ Fr } & \multirow{2}{*}{ P. value } \\
\cline { 2 - 7 } Pengetahuan & & Pil & \multicolumn{1}{c}{$\%$} & Suntik & $\%$ & & & \\
\hline Kurang & 2 & 3,17 & 6 & 9,52 & 8 & 12,6 & \multirow{2}{*}{0,002} \\
Cukup & 31 & 49,2 & 12 & 19 & 43 & 68,2 & \\
Baik & 3 & 4,76 & 9 & 14,2 & 12 & 19,0 & \\
\hline Jumlah & 36 & 42,7 & 27 & 57,1 & 63 & 100 & \\
\hline
\end{tabular}

Sumber : Olahan data primer (2018)

Tabel 7. Hubungan faktor umur dengan peminatan kontrasepsi Pil dan Suntik

\begin{tabular}{llllllll}
\hline \multirow{2}{*}{ Umur } & \multicolumn{3}{l}{ Jenis kontrasepsi } & \multirow{2}{*}{ Fr } & $\%$ & P. \\
\cline { 2 - 7 } & Pil & $\%$ & Suntik & $\%$ & & & value \\
\hline$<20$ tahun & 8 & 12,6 & 4 & 6,34 & 12 & 19,0 & \multirow{2}{*}{0,007} \\
$20-35$ & 26 & 41,2 & 13 & 36,5 & 39 & 61,9 & \\
$>35$ & 2 & 3,17 & 10 & 15,8 & 12 & 19,0 & \\
\hline Jumlah & 36 & 56.9 & 27 & 58,6 & 63 & 100 & \\
\hline
\end{tabular}

Sumber : olahan data primer (2018)

Tabel 8. Hubungan faktor Jumlah anak dengan peminatan Kontrasepsi Pil dan Suntik

\begin{tabular}{|c|c|c|c|c|c|c|c|}
\hline \multirow{2}{*}{ Jumlah Anak } & \multicolumn{4}{|c|}{ Jenis kontrasepsi } & \multirow{2}{*}{$\mathrm{Fr}$} & \multirow{2}{*}{$\%$} & \multirow{2}{*}{$\begin{array}{l}P . \\
\text { value }\end{array}$} \\
\hline & Pil & $\%$ & Suntik & $\%$ & & & \\
\hline $0-1$ & 6 & 9,52 & 6 & 9,52 & 12 & 19,0 & \multirow{3}{*}{0,009} \\
\hline $2-3$ & 27 & 42,8 & 11 & 17,4 & 38 & 60,3 & \\
\hline$>3$ & 3 & 4,7 & 10 & 15,8 & 13 & 20,6 & \\
\hline Jumlah & 36 & 57 & 27 & 42,7 & 63 & 100 & \\
\hline
\end{tabular}

Sumber : olahan data primer (2018)

Berdasarkan tabel 7, didapatkan hasil ibu yang berusia $<20$ tahun sebanyak 12 responden $(19,0 \%), 4$ responden $(6,34 \%)$ diantaranya menggunakan KB suntik dan 8 responden (12,6\%) menggunakan KB pil,dan ibu yang berusia 20 sampai 35 tahun sebanyak. 39 responden $(61,9 \%), 13$ responden $(36,5 \%)$ diantaranya menggunakan $\mathrm{KB}$ suntik dan 26 responden $(41,2 \%)$ menggunakan $\mathrm{KB}$ pil, Kemudian ibu yang berusia $>35$ tahun sebanyak 12 responden $(19,0 \%), \quad 10$ responden $(15,8 \%)$ diantaranya

menggunakan kontrasepsi Suntik dan 2 responden (3.17\%) menggunakan kontrasepsi Pil.

Hasil uji yang telah dilakukan dengan menggunakan uji statistik ChiSquare test mendapatkan hubungan antara Umur dengan penggunaan alat kontrasepsi jangka pendek dengan nilai p.value $0.007(<0,05)$. Ini berarti hipotesis nol $(\mathrm{H} 0)$ ditolak dan hipotesis alternative (Ha) diterima. Artinya, ada hubungan antara umur dengan peminatan alat kontrasepsi 
Suntik dan pil. Diperkuat juga nilai $X^{2}$ Hitung $(14,272)<X^{2}$ Tabel $(5,991)$ sehingga $\mathrm{HO}$ di tolak dan $\mathrm{Ha}$ diterima.

Berdasarkan Tabel 8 didapatkan hasil ibu yang memiliki anak 1 berjumlah 12 (19,0\%), 6 (9,52\%) menggunakan KB suntik dan 6 (9,52\%) menggunakan KB pil,dan ibu yang memiliki anak 2 sampai 3 sebanyak $38(60,3 \%), 11(17,4 \%)$ diantaranya menggunakan $\mathrm{KB}$ suntik dan 27 (42.8\%) menggunakan KB pil, Kemudian ibu yang mempunyai anak $>3$ sebanyak 13 (20,6\%), 10 (15,8\%), diantaranya menggunakan kontrasepsi Suntik dan 3 (4,7\%) diantaranya menggunakan kontrasepsi Pil.

Hasil uji yang telah dilakukan dengan menggunakan uji statistik ChiSquare test mendapatkan variable Jumlah anak dengan penggunaan alat kontrasepsi Suntik dan alat kontrasepsi pil nilai p.value 0.009 $(<0,05)$. Ini berarti hipotesis nol $(\mathrm{HO})$ ditolak dan hipotesis alternative $(\mathrm{Ha})$ diterima. Artinya, ada hubungan antara Jumlah anakdengan penggunaan alat kontrasepsi Suntik dan pil (Kontrasepsi jangka pendek) Diperkuat juga nilai $X^{2}$ Hitung $(10,602)$ $<\mathrm{X}^{2}$ Tabel $(5,991)$ sehingga $\mathrm{HO}$ di tolak dan Ha diterima.

\section{Hubungan Faktor pengetahuan dan Penggunaan kontrasepsi.}

Hasil uji analisis yang telah dilakukan dengan menggunakan uji statistik Chi-Square test mendapatkan variable pengetahuan dengan penggunaan alat kontrasepsi Suntik dan alat kontrasepsi pil nilai p.value $0.002(<0,05)$. Ini berarti hipotesis nol (H0) ditolak dan hipotesis alternative (Ha) diterima. Artinya, ada hubungan antara pengetahuan dengan peminatan kontrasepsi Pil dan Suntik sehingga $\mathrm{HO}$ di tolak dan $\mathrm{Ha}$ diterima.

Berdasarkan hasil tersebut masing-masing variabel memiliki hubungan dengan nilai korelasi yang kuat. Lembaga pendidikan baik formal maupun informal sebagai suatu sistem mempunyai pengaruh dalam pembentukan sikap dikarenakan keduanya meletakkan dasar pengertian dan konsep moral dalam arti individu (Hartono,2010). Teori ini menyimpulkan bahwa pemberian edukasi dan informasi mengenai alat kontrasepsi oleh pelayan kesehatan dapat mempengaruhi keputusan ibu untuk memilih alat kontrasepsi yang tepat sesuai dengan kebutuhannya.

Penelitian ini juga memperkuat penelitian sebelumnya yang dilakukan oleh Novianti, et all (2010) dengan judul penelitian "Faktor-Faktor Yang Berhubungan Dengan Pemilihan KB Hormonal Jenis Pil Dan Suntik Pada Akseptor KB Hormonal Golongan Usia Resiko Tinggi Di Puskesmas Cipageran Cimahi Utara Bulan Juli sampai Agustus 2010" dalam penelitian tersebut peneliti menemukan beberapa factor yang menjadi pengaruh peminat kontrasepsi jangka pendek yaitu factor pengetahuan, sikap, status ekonomi, dan pendidikan.

Memperkuat penelitian yang dilakukan oleh Dzauharoh Hadiyah (2015) yang berjudul beberepa factor yang berhubungan dengan penggunaan metode kontrasepsi jangka panjang (Studi pada akseptor KB dikabupaten siduarjo provinsi Jawa Timur) variable yang bersamasama berhubungan dengan penggunaan MKJP adalah pengetahuan, sikap akseptor terhadap MKJP, dan akses pelayanan KB. 


\section{Evi Ratna Pradila (2013)} dengan judul tingkat pengetahuan akseptor kontrasepsi Pil tentang efek samping kontrasepsi Pil di BPS Widjizati Margomulyo Bojonegoro yang menemukan terdapat hubungan antara pengetahuan ibu dengan pemakaian kontrasepsi Pil.

Notoatmodjo

mengungkapkan bahwa tingkat pengetahuan seseorang dipengaruhi oleh pendidikan, Umur, Jumlah anak. Tingkat pengetahuan ibu dalam penelitian ini dibagi menjadi tiga kategori yaitu baik, cukup dan kurang. Pengetahuan merupakan hasil dari tahu setelah orang melakukan pengindrahan terhadap objek tertentu. Pengetahuan atau rana kognitif merupakan domain yang sangat penting dalam membentuk tindakan seseorang sehingga yang lebih efektif, hasil penelitian menunjukan bahwa ada hubungan pengetahuan dengan pemakaian alat kontrasepsi.

Menurut Baharuddin (2009) pengetahuan adalah hasil belajar, pada saat seseorang belajar tentang sesuatu maka seseorang mengetahui sesuatu yang baru.Pengetahuan bukanlah hasil akhir melainkan lebih dari itu, pengetahuan adalah pembimbing atau pengarah bagi seseorang yang sedang belajar sesuatu yang baru.Satoto (2008) apa yang dianggap sebagai pengetahuan akan berubah status menjadi keyakinan biasa.

Dari hasil uji normalitas dengan menggunakan uji statistik chi-square menunjukkan bahwa terdapat hubungan antara tingkat pengetahuan, kontrasepsi Suntik dan pil. Pernyataan tersebut dapat dibuktikan dengan melihat pada tabel
7. Kondisi di lapangan menunjukkan bahwa KB Pil lebih banyak digunakan oleh akseptor $\mathrm{kb}$ yang berusia produktif yaitu 20 sampai 35 tahun dan berpengetahuan cukup mengenai alat kontrasepsi Pil dan Suntik. Hal ini disebabkan ibu yang beranggapan KB Pil lebih praktis penggunaannya dan mudah di dapatkan.

Peneliti berasumsi sebagian besar pengetahuan ibu mengenai penggunaan alat kontrasepsi yang rasional masih dalam kategori cukup, sehingga mempengaruhi ibu memilih alat kontrasepsi yang dianggap praktis dan yang paling banyak digunakan dimasyarakat. pengetahuan masyarakat dapat mempengaruhi penerimaan program $\mathrm{Kb}$, pengetahuan tentang program $\mathrm{Kb}$ termasuk tentang macam-macam jenis kontrasepsi akan meningkatkan keikutsertaan masyarakat dalam program $\mathrm{KB}$, sehingga perlu diberikan informasi dan peningkatan pemahaman terutama tentang $\mathrm{Kb}$ Pil dan Suntik.

\section{Hubungan Faktor Umur Dengan Penggunaan Kontrasepsi}

Pada penelitian sebelumya yang dilakukan oleh Hartika (2010) dengan judul gambaran pengetahuan, sikap, dan perilaku wanita usia 25 sampai 50 tahun mengenai kontrasepsi hormonal jenis suntik di rumah bersalin Gizar cikarang pada bulan agustus tahun 2010, menemukan bahwa wanita yang menggunakan kontrasepsi hormonal jenis suntik paling banyak berusian antara 20 sampai 30 tahun, dilihat dari data BKKBN 2009 dan SDKI 2009, hasil penelitian tersebut memiliki gambaran karakteristik umur 
yang tidak jauh berbeda, yaitu penggunaan kontrasepsi suntik kebanyakan digunakan oleh wanita muda usia 25 sampai 30 tahun.

Sinta Nuryati (2014) yang berjudul pengeruh faktor internal dan faktor eksternal terhadap pemilihan alat kontrasepsi pada akseptor KB baru di kabupaten bogor dalam penelitiannya sinta menemukan adanya pengaruh faktor internal yang terdiri dari umur, pendidikan, status bekerja, jumlah anak dan tujuan menggunakan alat kontrasepsi dengan pemilihan alat kontrasepsi pada akseptor Kb baru.

Antika D. (2014) yang berpendapat semakin tua usia seseorang akan meningkatkan kemungkinan untuk tidak menginginkan kehamilan lagi serta memilih kontrasepsi yang cocok dan efektif. Diperkuat oleh teori Hartanto (2010), efektifitas, biaya, dan kesinambungan pemakaian berpengaruh pada pemilihan metode kontrasepsi yang sesuai.

Umur dipandang suatu keadaan yang menjadi dasar kematangan dan perkembangan seseorang. Kematangan individu dapat dilihat langsung secara objektif dengan periode umur, sehingga sebagai proses pengetahuan, keterampilan, kemandirian terkait sejalan dengan bertambahnya umur individu (Muchsin 2000 dalam Hartika 2010).

Menurut Notoadmojo (2009), umur adalah salah satu faktor yang mempengaruhi perilaku seseorang dalam pemakaian alat kontrasepsi, mereka yang berumur tua mempunyai peluang lebih kecil untuk menggunakan alat kontrasepsi dengan yang berumur muda. Pola dasar penggunaan kontrasepsi yang rasional pada umur 20 sampai 30 adalah kontrasepsi yang mempunyai reserbilitas yang tinggi karena pada umur tersebut PUS masih berkeinginan untuk mempunyai anak, sedangkan pada umur > 30 tahun atas yang dianjurkan adalah yang mempunyai efektifitas yang tinggi dan dapat dipakai untuk jangka panjang.

Selaras dengan teori yang dikemukakan oleh Adryan (2008) bahwa pada umumnya umur akan mempengaruhi seseorang dalam menentukan pemilihan alat kontrasepsi karena biasanya ibu dengan usia muda (baru pertama kali menggunakan alat kontrasepsi) akan cenderung memilih alat kontrasepsi yang digunakan kebanyakan orang pakai.

Berdasarkan hasil penelitian Rata-rata umur responden yaitu 20 sampai 35 tahun dan hasil analisis yang di dapatkan diperoleh hubungan yang signifikan antara umur dan peminatan alat kontrasepsi Pil dan Suntik. Hal tersebut peneliti dapatkan berdasarkan wawancara saat penelitian,sebagaian besar ibu menggunakan kontrasepsi Pil dan suntik karena dari awal menggunakan alat kontrasepsi dan mengikuti alat kontrasepsi yang paling banyak digunakan di masyarakat.

Peneliti berasumsi Usia 20 sampai 35 tahun merupakan usia produktif pada wanita dan rentang usia untuk mengatur kehamilan dan jumlah anak sehingga karena alasan tersebut banyak responden yang menggunakan alat kontrasepsi jangka pendek agar lebih muda dilepas dan digunakan kembali. 


\section{Hubungan Jumlah Anak Dengan Penggunaan Kontrasepsi}

Selaras dengan penelitian sebelumya yang dilakukan oleh Hartika (2010) yang berjudul gambaran pengetahuan, sikap, dan perilaku wanita usia 25 sampai 50 tahun mengenai kontrasepsi hormonal jenis suntik di rumah bersalin Gizar cikarang pada bulan agustus tahun 2010. Menunjukkan bahwa wanita pengguna kontrasepsi jenis suntik yang memiliki jumlah anak kurang dari 2 sedang dalam masa perencanaan jumlah anak. Sedang wanita yang memiliki jumlah anak lebih dari 2 cenderung memilih kontrasepsi mantap yang lebih efektif dari pada kontasepsi suntik.

Sinta Nuryati (2014), yang berjudul pengeruh faktor internal dan factor eksternal terhadap pemilihan alat kontrasepsi pada akseptor KB baru di kabupaten bogor dalam penelitiannya sinta menemukan adanya pengaruh factor internal yang terdiri dari umur, pendidikan, status bekesrja, jumlah anak dan tujuan menggunakan alat kontrasepsi dengan pemilihan alat kontrasepsi pada akseptor Kb baru.

Aliyana et. al (2013), dengan judul Faktor yang berhubungan dengan penggunaan metode kontrasepsi hormonal pada akseptor KB dikelurahan pasar wajuh kecamatan pasar wajuh kabupaten buton selawesi tenggara peneliti manemukan hubungan yang signifikan antara jumlah anak hidup dengan penggunaan kontrasepsi hormonal.

Menurut BKKBN menyatakan bahwa paritas adalah banyaknya kelahiran hidup yang dipunyai oleh seorang wanita, umur wanita PUS kurang dari 30 tahun lebih biasanya memilih alat kontrasepsi Non Jangka Panjang, sebaliknya pada umur 30 tahun atau lebih biasanya lebih memilih alat kontrasepsi jangka panjang, hal ini sering didukung dengan tujuan atau alasan berKB. Pada usia kurang dari 30 tahun Biasanya jumlah anak 2 atau bahkan kurang sehingga mereka masih ingin mempunyai anak lagi maka alasan dan tujuan mereka berKB adalah untuk menunda kehamilan maka mereka lebih memilih alan kontrasepsi Non jangka panjang.

Menurut Nasution (2011), MKJP dapat dipakai dalam jangka waktu lama, efektif dan efesien untuk pemakaian menjarangkan kelahiran lebih dari 3 tahun. Menurut Hartanto (2010), Paritas atau jumlah anak harus diperhatikan setiap keluarga karena semakin banyak anak semakin banyak juga tanggungan kapala keluarga dalam mencukupi kebutuhan hidup, selain itu juga harus menjaga kesehatan reproduksi karena semakin sering malahirkan semakin rentang terhadap kesehatan ibu.

Berdasarkan hasil analisis ratarata jumlah anak responden terbanyak memiliki anak 2 sampai 5 berjumlah 38 responden $(60,3 \%)$ berdasarkan hasil analisis yang di dapatkan, diperoleh hubungan yang signifikan antara jumlah anak dan peminatan kontrasepsi Pil dan Suntik. Peneliti berasumsi masyarakat diwilayah kerja puskesmas global tibawa sebagian besar ingin memiliki keturunan lebih dari 2 sehingga mereka menggunakan kontrasepsi Pil dan Suntik, dan juga kontrasepsi pil dan suntik lebih mudah 
di dapatkan dan praktis penggunaannya, efek sampingnya kurang dan sangat cocok digunakan pada wanita yang berusia produktif. Responden yang berusia produktif 20 sampai 35 tahun lebih memilih menggunakan kontrasepsi pil karena mereka ingin memiliki anak lagi dan ada juga responden yang berusia > 35 tahun lebih memilih pil dibandingkan suntik kerena dari awal responden sudah menggunakan kontrasepsi pil dan responden tersebut enggan untuk mencoba jenis kontrasepsi yang lain dikarenakan responden lebih nyaman menggunakan pil dan ada juga yang takut dengan suntikan atau trauma pada suntikan dan tidak mau menggunakan kontrasepsi yang lain karena takut, banyak mitos-mitos yang beredar dimasyarakat bahwa menggunakan kontrasepsi yang lain banyak efek samping. Hal tersebut peneliti dapatkan dari hasil wawancara dengan beberapa responden.

\section{PENUTUP}

\section{Simpulan}

1. Ada hubungan yang signifikan antara umur dengan Peminatan kontrasepsi Pil dan Suntik dengan hasil $P$ Value 0.002 $(<0,05)$.

2. Ada hubungan yang signifikan antara pengetahuan dengan peminatan kontrasepsi Pil dan Suntik dengan hasil $P$ Value $0.007(<0,05)$

3. Ada hubungan yang signifikan antara jumlah anak dengan peminatan kontrasepsi Pil dan Suntik dengan Hasil $P$ Value $0.009(<0,05)$
1. Bagi Responden

Diharapkan mampu menambah pengetahuan tentang pentingnya Alat Kontrasepsi dan menambah wawasan responden

2. Bagi Profesi Kebidanan

Memberikan penyuluhan

kepada akseptor KB agar ibu mengerti dan mau selalu menggunakan alat kontrasepsi yang dipilih berdasarkan dukungan suami demi mengurangi permasalahan kependudukan diindonesia dan mengurai jumlah angka kematian ibu dan juga angka kematian bayi.

3. Bagi Peneliti Selanjutnya

Peneliti selanjutnya hendaknya lebih menambah atau mendalami tentang faktor - faktor yang berhubungan dengan peminatan kontrasepsi Pil dan Suntik agar menjadi dasar bagi penelitian lanjutan dan dapat menjadi salah satu bahan bagi penyempurna dalam pembelajaran khususnya dalam lingkup pelayanan KB.

4. Bagi institusi Pendidikan

Dapat menjadi bahan referensi perpustakaan dan menjadi bahan bagi mahasiswa yang akan melakukan penelitian selanjutnya khususnya tentang keluarga berencana agar penelitian ini lebih sempurna karena setiap tahun ilmu pengetahuan dan riset semakin meningkat atau selalu ada hal-hak yang baru.

\section{DAFTAR PUSTAKA}

Adryan. 2008, Keluarga berencana dan kesehatan produksi. Cetakan kesatu. Jakarta : EGC

\section{Saran}


Alyana et all , 2013. faktor yang berhubungan dengan metode kontrasepsi hormonal pada akseptor KB hormonal di kabupaten buton sulawesi tenggara. Jurnal kampus Universitas hasanudin Makassar.

Antika, D.A. 2014, Hubungan penggunaan KB suntik dengan siklus menstruasi pada akseptor KB. Yogyakarta

Baharudin, 2009. Pendidikan dan psikologi perkambangan, yogyakarta : As-Ruzz media 2009.

BKKBN. 2013. Rencana Aksi Nasional Pelayanan KB tahun 20142015.Jakarta : BKKBN

Dzauharoh, et all .2015, Beberapa faktor yang berhubungan dengan penggunaan metode kontrasepsi jangka panjang (Studi pada akseptor KB di Profinsi jawa timur). Jurnal menajemen kesehatan indinesia volume 3 no 1 . Universitas diponegoro. Semarang

Evi Ratna Pradila, 2013, Tingkat pengetahuan akseptor kontrasepsi pil tentang efek samping kontrasepsi pil di BPS Widziati Worgomulyo Bojonegoro. KTI, Stikes Kusuma Husada. Surakarta

Hanafi W, 2014. Keluarga berencana dan Kontrasepsi.

Hartika, 2010. Gambaran pengetahuan, sikap, dan perilaku wanita usia 25-50 tahun mengenai kontrasepsi hormonal jenis suntik dirumah bersalin Gizar Cikarang pada bulan agustus pada 2010. Skripsi Fakultas ilmu kedokteran dan ilmu kesehatan universitas negeri syarif hidayatullah. Jakarta 2010

Dinas BKKBN Provinsi Gorontalo. Profil Badan kependudukan dan keluarga berancana nasional provinsi Gorontalo 2016.

Dinas kesehatan Kabupaten Gorontalo.Profil kesehatan Kabupaten gorontalo 2016

Dinas kesehatan Provinsi Gorontalo. Profil kesehatan provinsi gorontalo 2016

Fienalia, Rainy Alus. 2013. Faktorfaktor yang berhubungan dengan penggunaan MKJP Diwilayah Kerja Puskesmas Pancoran Mas. Program Studi Kesehatan Masyarakat. Skripsi. Universitas Islam Negeri Syarif Hidayatullah. Jakarta

Hartono, 2010.Keluarga Berencana dan

Kontrasepsi.Jakarta.Pustaka Sinar Harapan

Irianto.Koes.2014. Pelayanan keluarga berancana. EGC. Jakarta Istantri.2013.sejarah kontrasepsi.https://sejarahperkembangan-kontrasepsidulu-dan-kinil. Diakses 20-februari-2013

Nasution. 2011, faktor yang mempengaruhi penggunaan MKJP di enam wilayah indonesia. Pusat penelitian dan pengembangan $\mathrm{KB}$ : BKKBN

Novianti et al. 2012. www.stikesayani.ac.id/ pu blikasilejournal/filesx/2012/2012 08/201208-001.pdf.Di Akses 0108-2012

Notoadmodjo. 2014, metodeologi penelitian. Jakarta : Rineka cipta 
Puskesmas Global Tibawa. Profil puskesmas Global Tibawa

Pontoh.L.N.2015. Hubungan

pengetahuan dan sikap suami tentang keluarga

berencana dengan motifasi pen

ggunaan alat kontrasepsi pria di desa Buroko. Skripsi.

Universitas Muhammadiyah Gorontalo,Gorontalo.

Qs.An-Nisa Ayat 9

Setiawan.2010.Metodologi penelitian kebidanan Yogyakarta nurhamdika

Satoto. 2001. The Right Condom on The Right Place. Semarang.

Sinta Nuryati.2014 Pengaruh faktor internal dan faktor eksternal terhadap pemilihan alat kontrasepsi pada akseptor KB baru di Kabupaten Bogor. Jurnal ilmiah kesehatan diagnosis polume 5 nomor 5 tahun 2014 .

WHO, 2009. Medical eligibility Criteria for contracetive user. Genava 